\title{
ENTIONELLA MONENSIS SP.NOV., AN ENTONISCID PARASITE OF THE SPIDER CRAB EURYNOME ASPERA (PENNANT)
}

\author{
By R. G. HaRTNOLL \\ Marine Biological Station, Port Erin, Isle of Man
}

(Text-figs. I-8)

The family Entoniscidae (Isopoda-Epicaridea) is included in the superfamily Bopyrina, which comprises the families Bopyridae, Dajidae and Entoniscidae. The Bopyridae are parasitic in the branchial cavity or on the abdomen of decapods, mainly Macrura and Anomura. The Dajidae occur in the incubatory chamber or on the dorsal surface of mysids and euphausiids, and rarely on Brachyura. The Entoniscidae are found in the visceral cavity of Anomura and Brachyura (an exception is Synalpheion, in a macruran, Coutière I908), surrounded by a membrane of host origin, and communicating with the branchial cavity of the host by a pore. Together with this internal habitat the family has extreme morphological specialization. Females of the Bopyridae have distinct thoracic segmentation and well-developed peraeopods; in the Dajidae the peraeopods are distinct, but segmentation is less evident; in adult females of the Entoniscidae, however, the peraeopods consist of only the enlarged oostegites, with rudimentary endopodites in some species, and the thorax has only traces of segmentation.

Giard \& Bonnier (I887) considered that entoniscids were morphologically and physiologically external parasites, that the sheath was formed by invagination of the body wall of the host, and that the external medium circulated within it. However, Miyashita (I94I) considers that there is little, if any, circulation, and shows that in Entionella fluviatilis Miyashita the fluid within the sheath is indistinguishable from the haemolymph of the host. Veillet (I945) has shown that in Portunion maenadis (Giard) the younger stages are totally internal; the host secretes a sheath, which only later develops an opening to the exterior. The family may therefore be considered truly endoparasitic.

The Entoniscidae have been studied in only a few areas, and it is probable that only a small proportion of the total species have been recorded. The most recent survey of the family is by Shiino (1942). There are thirty-one known species, which are distributed as follows.

Europe, I2 spp.; South America-Atlantic coast, 5 spp.; North AmericaAtlantic coast, 3 spp.; North America-Pacific coast, I sp.; Japan, Io spp. 
Two species have been recorded previously from British waters, Pinnotherion vermiforme from Pinnotheres pisum and Portunion maenadis from Carcinus maenas (Marine Biological Association, 1957, pp. 206-7).

\section{Material examined}

I02 specimens of Eurynome aspera were collected offshore around the south of the Isle of Man, and two were infected by the entoniscid described below. A male crab, carapace length $17.5 \mathrm{~mm}$, dredged on 7 November 1958 in $40 \mathrm{~m}$ approximately $6 \mathrm{~km}$ west of Fleshwick contained two ripening female parasites. A second male, carapace length $16.5 \mathrm{~mm}$, dredged on 24 February I959 in $65 \mathrm{~m}$ approximately $9 \mathrm{~km}$ west of Calf Sound contained an ovigerous female and a male.

\section{Genus Entionella Miyashita I94I}

Female. First oostegite with well-developed ascendant, lateral and recurrent lobes. Thorax without ovarian processes. Heart on third abdominal segment. Convoluted pleural lamellae on first and second abdominal segments only.

Male. Peraeopods jointed. Thoracic terga expanded laterally as flat plates. Abdominal segments I-4 with hyposphenians ('crochets ventraux médians', Giard \& Bonnier, 1887).

\section{Description}

\section{Entionella monensis sp.nov.}

Female. The following description is of the ovigerous specimen (Fig. 2). The cephalogaster is bilobed and swollen; ventrally it bears the first and second antennae, which are rounded lobes flanking the mouth (Fig. 3, an I, 2). Posterior to these are the maxillipedes (Fig. 3, $m x p$ ), each having a bilobed prominence, which bears a free flattened third lobe dorsally. The respiratory folds $(r f)$ or 'corps spongieux' of Giard \& Bonnier (1887) are small and simple, and ventral to the maxillipedes.

The thorax is dull orange in colour, of even width and without ovarian processes. The peraeopods are represented only by five pairs of oostegites which arise dorsally, the reduced dorsal surface of the thorax lying between their bases (Fig. 4, dst). Oostegites $2-5$ form the brood chamber, but this is open and eggs lie between the oostegites and the host membrane. Oostegite I is large and has three lobes; the ascendant and lateral lobes are both folded and hood-like, while the recurrent lobe is large and flat, and lies along the lateral and ventral surfaces of the thorax enfolded by oostegites 2-5 (Fig. I). According to Giard \& Bonnier (I887) the function of the first pair of oostegites is to agitate the contents of the brood chamber, and to prevent the eggs and 
embryos being crushed. However as the oostegites are more or less immobile, the latter is probably their principal use. There is a blood vessel, the marginal sinus $(m s)$, which emerges from the base of the oostegite and passes around the free borders of all three lobes. On the ascendant lobe there is a median vessel $(m v)$ which joins the marginal sinus distally. There are two branching blood vessels on the lateral lobe, and one median vessel on the recurrent lobe which sends branches towards the marginal sinus (Fig. 2). The ascendant lobe is stiffened by a clear firm rod which runs alongside the median vessel (Fig. 2, $s r)$. The other oostegites are without prominent blood vessels or stiffening supports.

Oostegite 2 encloses the base of oostegite I, and oostegites 3-5 enclose the rest of the thorax, overlapping to form the brood chamber (Fig. I). They extend dorsally before being reflexed ventrally, and thus form dorsal pouches (Fig. 4). Their margins are slightly irregular, but are nowhere strongly dissected. In the angle between the thorax and abdomen the bases of the fifth oostegites are swollen and folded to form a tubular structure on each side. This may be a receptaculum seminis, such as occurs in a corresponding position in Pinnotherion vermiforme (Atkins, 1933). Traces of segmentation are visible on the thorax, corresponding with the oostegites.

The abdomen (Fig. 5) is sharply reflexed along the dorsal surface of the thorax, and is approximately half the diameter of the thorax. There are five segments bearing appendages, and a small sixth segment which is bifid and situated ventrally (Fig. 5, las). The heart (Fig. 2, ht) forms a hemispherical swelling on the dorsal surface of the third segment. Each of the five appendagebearing segments has ventrally a pair of lamellae, which are the uniramous pleopods. They overlap the lamellae of the preceding segment, and in segments I-4 one of the pair overlaps the other medially, without, however, showing a regular pattern of imbrication in the three specimens examined. Another series of structures, the pleural lamellae, arises from the bases of the pleopods. In segments one and two they are complex convoluted lamellae, and in segments $3-5$ they are simple styliform processes. Giard \& Bonnier (I887) suggest that they may have a respiratory function.

The incubatory chamber was packed with round, pale orange eggs, $0.15 \mathrm{~mm}$ in diameter.

The two ripening females differ slightly from the above description. The segmentation of the thorax is more marked, and the oostegites are smaller, especially the first. Oostegites 3-5 do not form dorsal pouches. The ovaries contain tightly packed polygonal eggs, orange in colour, diameter $0.1 \mathrm{~mm}$ approximately.

The distance from the anterior end of the cephalogaster to the rear of the thorax, and the length of the abdomen, respectively, for the three female specimens were: ovigerous female $-7.0,5.0 \mathrm{~mm}$; first ripening female -6.4 , $4 \cdot 8 \mathrm{~mm}$; second ripening female $-7 \cdot 2,5 \cdot 4 \mathrm{~mm}$. 


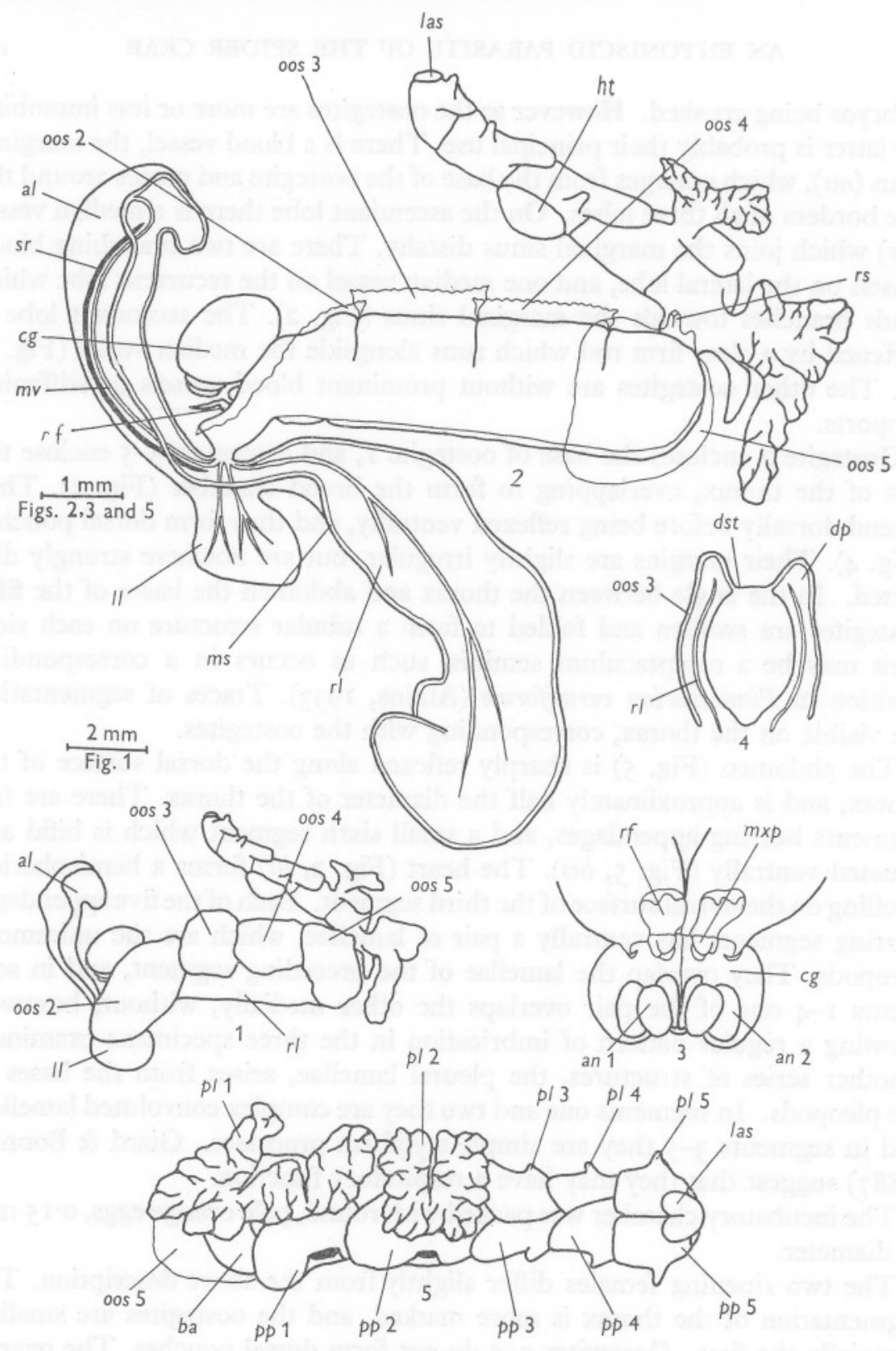

Fig. I. Oostegites in situ.

Figs. I-5. Entionella monensis, female.

Fig. 2. Oostegites 2,3 and 4 cut off at base.

Fig. 3. Cephalogaster ventral view.

Fig. 4. Diagrammatic transverse section at region of third oostegite.

Fig. 5. Abdomen, ventral view.

Abbreviations: al, ascendant lobe of first oostegite; an I-2, antennae $\mathrm{I}-2 ; b a$, base of abdomen; $c g$, cephalogaster; $d p$, dorsal pouch; $d s t$, dorsal surface of thorax; $h t$, heart; las, last abdominal segment; $l l$, lateral lobe of first oostegite; $m s$, marginal sinus; $m v$, median vessel; $m x p$, maxillipede; oos $\mathrm{I}-5$, oostegites $\mathrm{I}-5$; $p l \mathrm{I}-5$, pleural lamellae $\mathrm{I}-5 ; p p \mathrm{I}-5$, pleopods $\mathrm{I}-5$; $r f$, respiratory folds;' $r l$, recurrent lobe of first oostegite; $r s$, receptaculum seminis; $s r$, stiffening rod. 
Male (Fig. 6). Only one specimen has been found, which occurred in the visceral cavity of the crab, separated from the female by the host membrane. This may be the normal position, for Atkins (I933) found that in Pinnotherion vermiforme all the males discovered occurred free in the body cavity of the host. In other species of entoniscid the male occurs within the incubatory chamber or on the surface of the female.

The total length is $\mathrm{r} .65 \mathrm{~mm}$. The general colour is pale, but the hepatopancreas gives an orange colour to the posterior thoracic and anterior abdominal segments, and there are several scattered brown chromatophores.

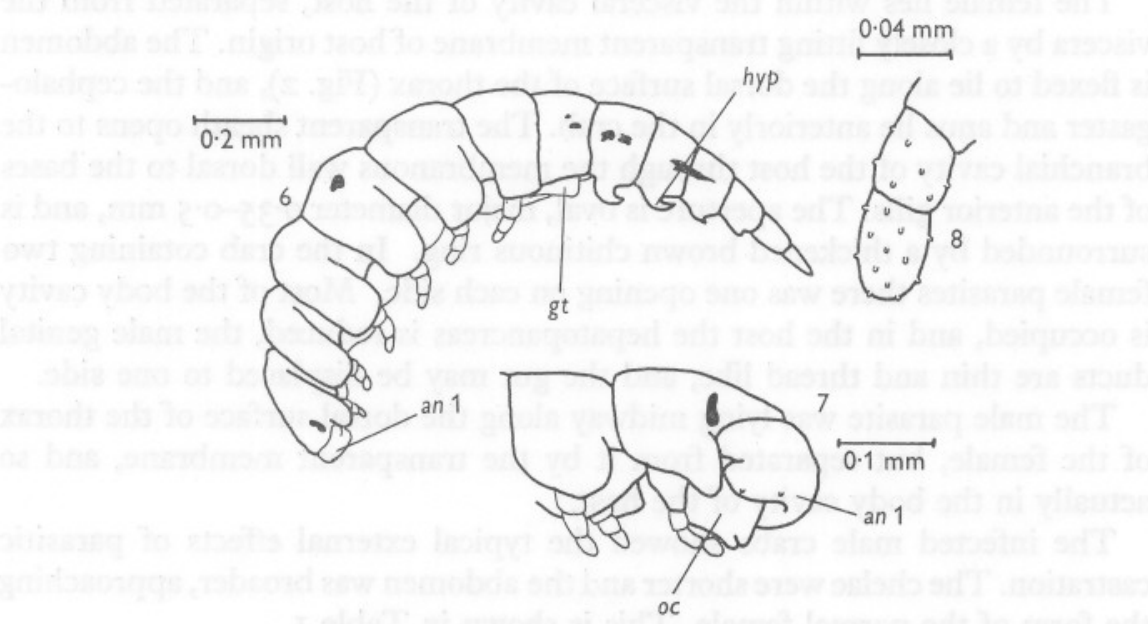

Figs. 6-8. Entionella monensis, male.

Fig. 6. Lateral view.

Fig. 7. Head.

Fig. 8. Fourth peraeopod.

Abbreviations: an I, first antenna; gt, genital tubercle; hyp, hyposphenians; $o c$, oral cone.

The head is blunt, and has a curved boss around its anterior margin. This is formed of the enlarged first antennae (an $\mathrm{I}$ ), which in most other species are swellings on either side of the anterior of the head. The second antennae are absent, as in Entionella okayamaensis Shiino. Ventrally there is a suctorial oral cone which encloses the mandibles; it has no scale-like projections on the lower lip. No maxillae or maxillipedes could be found.

The thorax has six free segments, the third to the eighth, the first and second being fused with the head. The terga of segments 2-7 are produced laterally as broad flat processes. There are six pairs of peraeopods, on segments $2-7$, segment 8 lacking appendages but bearing a pair of lateral genital tubercles. The posterior peraeopods are slightly larger than the anterior ones, and all are of three segments, the terminal one rounded. The two distal segments bear a number of small blunt tubercles (Fig. 8). 
The first four abdominal segments have mid-ventral projections or hyposphenians ('crochets ventraux médians', Giard \& Bonnier, 1887), those on segments one and two being strongly hooked (hyp). The last segment, the sixth plus the telson, is pointed and unforked.

Type specimens have been deposited at the British Museum (Nat. Hist.). The ovigerous female has been selected as the holotype (register no. I959.vi. 22. I) and the male as an allotype (register no. 1959.vi.22.2).

\section{Relation with host}

The female lies within the visceral cavity of the host, separated from the viscera by a closely fitting transparent membrane of host origin. The abdomen is flexed to lie along the dorsal surface of the thorax (Fig. 2), and the cephalogaster and anus lie anteriorly in the crab. The transparent sheath opens to the branchial cavity of the host through the membranous wall dorsal to the bases of the anterior gills. The aperture is oval, major diameter $0.35-0.5 \mathrm{~mm}$, and is surrounded by a thickened brown chitinous ring. In the crab cotaining two female parasites there was one opening on each side. Most of the body cavity is occupied, and in the host the hepatopancreas is reduced, the male genital ducts are thin and thread like, and the gut may be displaced to one side.

The male parasite was lying midway along the dorsal surface of the thorax of the female, but separated from it by the transparent membrane, and so actually in the body cavity of the host.

The infected male crabs showed the typical external effects of parasitic castration. The chelae were shorter and the abdomen was broader, approaching the form of the normal female. This is shown in Table I.

TABLE 1. A COMPARISON OF INFECTED MALE CRABS WITH NORMAL MALES AND FEMALES

\begin{tabular}{|c|c|c|c|c|c|}
\hline $\begin{array}{c}\text { Sex and condition } \\
\text { of crab }\end{array}$ & $\begin{array}{c}\text { Carapace } \\
\text { length } \\
(\mathrm{mm})\end{array}$ & $\begin{array}{l}\text { Chelar } \\
\text { propodus } \\
\text { length } \\
(\mathrm{mm})\end{array}$ & $\begin{array}{c}\text { Ratio: } \\
\text { carapace L. } \\
\text { propodus L. }\end{array}$ & $\begin{array}{l}\text { Width of } \\
\text { A.s. } 4 \\
\text { (mm) }\end{array}$ & $\begin{array}{c}\text { Ratio: } \\
\text { carapace } \mathrm{L} \text {. } \\
\text { width of } \\
\text { A.s. } 4\end{array}$ \\
\hline Parasitized male & $17 \cdot 5$ & 6.6 & 2.65 & 2.55 & $6 \cdot 86$ \\
\hline Parasitized male & 16.5 & $6 \cdot 4$ & $2 \cdot 56$ & $2 \cdot 20$ & $7 \cdot 50$ \\
\hline Normal male & 16.5 & 10.4 & $I \cdot 59$ & $\mathrm{I} \cdot 55$ & 10.64 \\
\hline Normal male & 18.0 & $12 \cdot 2$ & $\mathrm{I} \cdot 47$ & I. 65 & 10.90 \\
\hline Normal female & $16 \cdot 0$ & $5 \cdot 4$ & $2 \cdot 96$ & 3.85 & $4 \cdot 16$ \\
\hline Normal female & I7.0 & $6 \cdot 0$ & $2 \cdot 83$ & $4 \cdot 10$ & $4 \cdot 15$ \\
\hline
\end{tabular}

\section{DISCUSSION}

Entionella monensis sp.nov. is included in the genus Entionella because the female has no ovarian processes, and there are folded pleural lamellae only on the first two abdominal segments. The three species of the genus may be distinguished by means of Table 2 (partly based on that of Shiino, I954).

E. fluviatilis and E. okayamaensis both occur in Japan, in hosts spending part of their life in fresh and brackish water. The discovery of $E$. monensis 
extends the range of the genus to European waters. There are four other genera which also occur in both of these areas: Entoniscus Müller, Pinnotherion Giard \& Bonnier, Portunion Giard \& Bonnier and Cancrion Giard \& Bonnier.

\section{TABLE 2. CHARACTERS SEPARATING THE SPECIES OF THE} GENUS ENTIONELLA

\begin{tabular}{|c|c|c|c|c|}
\hline \multirow[b]{2}{*}{ Female } & & E. fluviatilis & E. okayamaensis & E. monensis \\
\hline & Oostegite I & $\begin{array}{l}\text { All three lobes } \\
\text { folded }\end{array}$ & $\begin{array}{l}\text { Recurrent lobe not } \\
\text { folded; many } \\
\text { secondary pockets }\end{array}$ & $\begin{array}{l}\text { Recurrent lobe } \\
\text { not folded; no } \\
\text { secondary pockets }\end{array}$ \\
\hline \multirow{5}{*}{ Male } & Pleural lamella I & No stalk & Long stalk & No stalk \\
\hline & Pleural lamellae $3-5$ & Distinct & Indistinct & Distinct \\
\hline & $\begin{array}{l}\text { Last abdominal } \\
\text { segment }\end{array}$ & Deeply bifid & Shallowly bifid & Undivided \\
\hline & Thoracic segment 8 & No expansion & Lateral expansions & Lateral expansions \\
\hline & Thoracic segment 2 & $\begin{array}{l}\text { Not fused with } \\
\text { cephalon }\end{array}$ & $\begin{array}{l}\text { Fused with } \\
\text { cephalon }\end{array}$ & $\begin{array}{l}\text { Fused with } \\
\text { cephalon }\end{array}$ \\
\hline
\end{tabular}

\section{SUMMARY}

The relationships of the Entoniscidae to the other families of the Bopyrinae are briefly discussed. The nature of the parasitism of the family is considered. The characters of the genus Entionella are given, and a new species, $E$. monensis is described (mature female and mature male). Its relations with the host, the spider crab Eurynome aspera, are described. A table is provided to separate the species of the genus Entionella.

\section{REFERENCES}

Atkins, D., 1933. Pinnotherion vermiforme Giard \& Bonnier, an entoniscid infecting Pinnotheres pisum. Proc. zool. Soc. Lond., pp. 319-63.

Coutrìre, H., 1908. Sur le Synalpheion giardi n.gen., n.sp., entoniscien parasite d'un synalphée. C.R. Acad. Sci., Paris., Vol. 146 pp. 1333-5.

Giard, A. \& Bonnier, J., I887. Contributions a l'étude des bopyriens. Trav. Sta. zool. Wimereux, T. 5, pp. I-252.

Marine Biological Association, 1957. Plymouth Marine Fauna, 3rd edition, $457 \mathrm{pp}$.

MryashitA, Y., I94I. Observations on an entoniscid parasite of Eriocheir japonicus de Haan, Entionella fluviatilis n.g., n.sp. Fap. F. Zool., Vol. 9, pp. 25I-67.

SHIINo, S. M., I942. On the parasitic isopods of the family Entoniscidae, especially those found in the vicinity of Seto. Mem. Coll. Sci. Kyoto, Ser. B, Vol. I7, pp. $37-76$.

SHIINO, S. M., I954. A new fresh-water entoniscid isopod, Entionella okayamaensis n.sp. Rep. Fac. Fish. prefec. Univ. Mie, Vol. I, pp. 239-46.

VeILLET, A., I945. Recherches sur le parasitisme des crabes et des galathées par les rhizocéphales et des épicarides. Ann. Inst. océanogr. Monaco., Vol. 23, pp. 193-34I. 